TOUSSAINT (A.). - La route des iles. Paris. S.E.V.P.E.N. École Pratique des Hautes Études. VIe section. Coleção "Ports, routes, trafics". 1967.

As ilhas de que trata o presente volume são as Mascarenhas, pequeno arquipélago situado no Oceano Indico, a leste da grande Ilha de Madagascar.

O Autor, que já publicou em 1961, uma Histoire de l'Océan Indien procurou desta vez analisar o movimento da navegação num setor particular dêste Oceano, e, para fazê-lo pesquisou sistemàticamente os documentos conservados nos arquivos da Ilha Maurícia e no de sua vizinha, a Ilha da Reunião.

Seu estudo limita-se ao período compreendido entre 1773 a 1830 , ou seja depois do estabelecimento duma Côrte do Almirantado nas Mascarenhas até a conquista dessas ilhas pela Inglaterra durante as guerras napoleônicas - período durante o qual o Oceano Índico desempenhou um papel de primeira ordem na conjuntura econômica.

Até agora representava-se geralmente as Mascarenhas como uma das escalas da Rota das Indias, mas o Autor demonstra que elas foram na realidade, durante êsse período, o ponto final de uma verdadeira "rota das ilhas", freqüentada por mercadores do mundo inteiro, e o centro de um comércio onde o tráfico negreiro e a pirataria maritima tinham um papel importante.

A obra é acompanhada de numeras estatísticas e de noventa e três documentos escolhidos entre os "relatórios do mar" mais típicos e ilustrado com mapas e gráficos.

\title{
E. S.P.
}

CAVIGNAC (J.). - Jean Pellet, commerçant en gros. Contribution a l'étude $d u$ négoce bordelais au XVIIle siècle. Paris. S.E.V.P.E.N. Publicação da École Pratique des Hautes Etudes. VIe section. Coleção "Affaires et Gens d'Affaires". 1967.

Após ter traçado numa primeira parte as condições técnicas, econômicas, jurídicas e financeiras nas quais se desenvolve o grande comércio maritimo no século XVIII, o Autor empreendeu a descrição da atividade de um negociante particularmente representativo de Bordéus, então o primeiro pôrto do Reino de França. O comércio de Bordéus no século XVIII, é antes de mais nada o das "Ilhas do Açúcar", e especialmente na primeira metade do século, a Martinica. Esse comércio atlântico domina todo o comércio europeu; os produtos coloniais são redistribuídos em todo o sul da França por comissários e "mercadores droguistas".

O mercado espanhol se fecha mais ou menos em 1726 à redistribuição dos produtos das colônias francesas e Pellet torna-se então o correspondente em Bordéus da "Companhia real de Caracas", fundada pelo rei da Espanha para valorização da Venezuela. Graças à sua fortuna e às suas relações comerciais, Pellet torna-se ràpidamente um personagem de vulto em Bordéus, e o Autor, numa terceira parte de sua obra, estuda as conseqüências sociais da sua fortuna. 
Uma escôlha importante de peças justificativas, de ilustrações e de gráficos permitem levar em conta, de maneira completa, as condições técnicas e financeiras do tráfico marítimo do grande pôrto bordelês.

E. S: $P$.

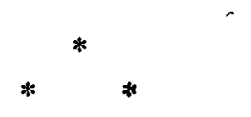

MEYER (J.). - La noblesse bretonne au XVIIIe siècle. Paris. S.E.V.P.E.N. Publicação da "École Pratique des Hautes Études. VIe section". Coleção "Bibliothèque Générale". 1967.

Esse ensaio devotado à nobreza bretã pretende ser ao mesmo tempo quantitativo - na medida em que os documentos o permitirem - institucional e psicológico. A obra estrutura-se, pois, sôbre uma dialética permanente que não cessa de multiplicar ambigüidades, falhas, contradições. Nenhuma nobreza, com efeito, não é mais original, mais particularista, mais fechada nos seus usos e costumes, do que a nobreza bretã. Foi acentuado muitas vêzes a "nova nobreza": nenhuma outra sofreu como ela as esquematizações abusivas por ocasião das controvérsias políticas dos séculos XVII e XVIII. Fundamentada sôbre as precauções de um Letaconnoux e mais ainda de Henri Sée, essa pesquisa deixa entrever a parte, muitas vêzes subestimadas do Oeste na economia francesa. A nobreza bretã participa dessa vida econômica mais do que se tem o hábito de dizer. Como Michelet gostava já de fazer notar, a França do Antigo Regime era diversificada.

$$
\text { E. S. P. }
$$

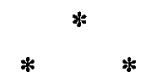

FINA (Wilson Maia). - $O$ chão de Piratininga. Editôra Anhambi S. A. São Paulo, 1965, 125 páginas, formato $0,16 \times 0,23$, ilustrado com três mapas (encarte).

Nunca vimos um arquiteto tão historiador, ou melhor, uma história tão tècnicamente arquitetada. Temos a impressão que depois de cada pesquisa, depois de cada página, voltava a vê-la, admirando suas carcterísticas estéticas, de régua de cálculo em punho, buscando ver na pesquisa, uma cornija que colocara, apoiando uma fôlha de acanto do passado.

O segrêdo de sua técnica reside no equilíbrio, na clareza e conceituação dos fatos que constituem sua razão de ser.

No capitulo I. - $O$ campo de Piratininga, inicia, levantando uma problemática, evitando assim a formação perigosa de um mito. Teria Piratininga existido? Seria um rio? Seria taba de índios?... bairro? No final, depois de situar sua problemática, conclui mostrando que Piratininga era um bairro em técnica urbanística moderna e uma paragem no sentido histórico. 